\title{
Purification of Methylthymol Blue by Solvent Extraction
}

\author{
Hiroaki Nakayama, Satoshi Tachiyashik and Etsuyo Shimizu \\ Laboratory of Chemistry, Kagawa Nutrition College, Sakado, Saitama 350-02
}

\begin{abstract}
A new method has been established for puritying Methylthymol Blue (MTB; 3,3'-bis[N,N-bis(carboxymethyl)aminomethyl]thymolsulfonphthalein) by liquid-liquid distribution between 1-butanol and aqueous hydrochloric acid. A free acid form of MTB, $\mathrm{H}_{6} M T B \cdot 3 \mathrm{H}_{2} \mathrm{O}$, was easily obtained in large scale $(10 \mathrm{mmol})$ with good yield $(70 \%)$ and high purity, free from Semi-Methylthymol Blue (SMTB) and iminodiacetic acid (IDA). The distribution ratios of MTB, SMTB and IDA between the two phases are also reported.
\end{abstract}

Keywords Methylthymol Blue, purification, 1-butanol, solvent extraction, distribution ratio

Sulfophthalein complexons have been used in spectrophotometry ${ }^{1,2}$ as well as metallochromic indicators in chelatometry ${ }^{2,3}$ for the chemical analysis of metals. Their ternary and quaternary complexes with rare earth metals have recently been of particular interest. ${ }^{4}$ In many studies commercial indicators were used without any purification: Since commercial indicators contain a considerable amount of impurities, such as iminodiacetic acid (IDA) and byproducts of their syntheses, it is highly desirable to develop a method for improving their purity.

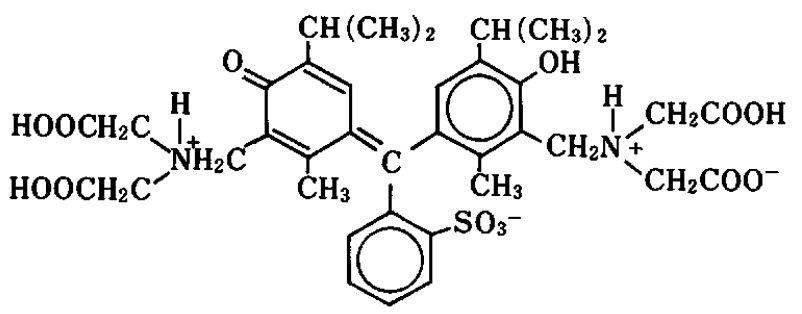

MTB

Some chromatographic methods have been proposed $^{6-9}$ for the purification of 3,3'-bis[ $N, N$-bis (carboxymethyl)aminomethyl]thymolsulfonphthalein (Methylthymol Blue, MTB). They are, however, insufficient for purifying it in large amounts. The present paper reports on a new method for purifying MTB with solvent extraction. This method can be readily practiced on a large scale, both in the laboratory and factory, without any expensive instruments. The stable form of free acid $\mathrm{H}_{6} \mathrm{MTB} \cdot 3 \mathrm{H}_{2} \mathrm{O}$ was obtained with high purity.

\section{Experimental}

\section{Apparatus}

Absorption spectra were recorded on a Hitachi 320 spectrophotometer. The $\mathrm{pH}$ was measured with a PHM-84 pH meter (Radiometer, Copenhagen, Denmark).

\section{Materials}

Hydrochloric acid $(\mathrm{HCl}$, Wako Pure Chemical Ind., SSG), IDA (Dojindo Lab.), potassium nitrate (Merck, Sprapur), borate buffer (Horiba, pH $9.180 \pm 0.003$ at $25^{\circ} \mathrm{C}$ ) and ninhydrin reagent set (Wako, for amino acid analysis) were all used as purchased. Semi-Methylthymol Blue (SMTB) was purified as described in a previous paper. ${ }^{6}$ H-form of SP-Sephadex (Pharmacia, C-25) and Cl-form of DEAE-Sephadex (Pharmacia, A25) were used after conditioning with $1 \mathrm{M}$ sodium hydroxide $(\mathrm{NaOH}), 1 \mathrm{M} \mathrm{HCl}$, and finally with water. Other reagents, including 1-butanol $(\mathrm{BuOH})$, were all reagent grade (Wako) and were used as received.

Estimation of purity by Sephadex ion exchange chromatography

The content of Thymol Blue(TB), SMTB, and MTB were determined by column chromatography on SPSephadex ( $18 \mathrm{~mm}$ i.d. $\times 260 \mathrm{~mm}$ ) using $0.01 \mathrm{M} \mathrm{HCl}$ as an eluent. ${ }^{6}$ The amount of each compound was estimated from the area of the corresponding peak in an elution curve, obtained by measuring the absorbance of effluent at $440 \mathrm{~nm}$.

A DEAE-Sephadex column $(25 \mathrm{~mm}$ i.d. $\times 440 \mathrm{~mm})$ was used to determine the amount of IDA in crude MTB. The $\mathrm{pH}$ of a sample solution was adjusted to 5 with $\mathrm{NaOH}$, and charged to the column. Fifty milliliters of $0.01 \mathrm{M} \mathrm{HCl}$ and $50 \mathrm{ml}$ of $0.05 \mathrm{M} \mathrm{HCl}$ were used successively as the eluent. The order of elution was glycine (impurity contained in IDA purchased), IDA, an unidentified dye, and MTB. The amount of IDA was determined by ninhydrin colorimetry. 


\section{Determination of the liquid-liquid distribution ratio of $M T B, S M T B, T B$, and $I D A$}

Aqueous solutions were prepared for MTB $(0.1 \mathrm{mM})$, SMTB $(0.1 \mathrm{mM})$, or IDA $(20 \mathrm{mM})$ with various $\mathrm{pH}$ under a constant chloride concentration of $0.25 \mathrm{M}$ $(\mathrm{HCl}-\mathrm{NaCl})$. A mixture of $8 \mathrm{ml}$ each of the aqueous solution and $\mathrm{BuOH}$ was shaken for $5 \mathrm{~min}$ at room temperature $\left(20^{\circ} \pm 2^{\circ} \mathrm{C}\right)$. The $\mathrm{pH}$ of the aqueous phase was measured. As for TB, its BuOH solution (0.2 mM) was shaken together with $0.25 \mathrm{M}$ aqueous $\mathrm{NaCl}$ or with water. The distribution ratios of MTB, SMTB and TB between the $\mathrm{BuOH}$ and the aqueous phases were determined by measuring the absorbance of the two phases at the wavelength of absorption maxima ${ }^{10,14}$ of the dyes. The distribution ratio of IDA was determined by ninhydrin colorimetry of IDA in each phase solution at pH 5 .

\section{Synthesis and pretreatment of crude Methylthymol Bhue}

Two milliliters of formaldehyde (37\%) were added to a mixture of Thymol Blue (TB) (4 g), IDA ( $3 \mathrm{~g}), \mathrm{NaOH}$ $(1 \mathrm{~g})$ and acetic acid $(50 \mathrm{ml})$ at $55^{\circ} \mathrm{C}$. The solution was kept at $55^{\circ} \mathrm{C}$ for $7 \mathrm{~h}$ under stirring. ${ }^{?}$

Twenty-five milliliters of diethyl ether were added to $10 \mathrm{ml}$ of an acetic acid solution of synthetic mixture at $40^{\circ} \mathrm{C}$ to precipitate crude MTB. After the supernatant decanted off, the precipitate was dissolved in $3 \mathrm{ml}$ of water followed by the addition of $4 \mathrm{ml}$ of $37 \% \mathrm{HCl}$. The solution was evaporated under vacuum at room temperature, and the residue was dissolved into $70 \mathrm{ml}$ of BuOH. An insoluble solid was filtered off, and the filtrate was supplied for solvent extraction.

\section{Recommended procedure for purification of $M T B$}

Seventeen milliliters of $0.1 \mathrm{M}$ aqueous $\mathrm{NaOH}$ were added to the $70 \mathrm{ml}$ of a BuOH solution obtained by the above-mentioned method; the mixture was shaken for $5 \mathrm{~min}$. After the pH of the aqueous layer was confirmed to be $1.4-1.5^{10}$, the layer was removed. To the remaining BuOH layer, $2 \mathrm{ml}$ of $0.03 \mathrm{M} \mathrm{HCl}$ was added. After shaking the resultant mixture the aqueous layer was removed. The extraction procedure was repeated 5 times.

To the BuOH solution obtained as mentioned above, $10 \mathrm{ml}$ of $0.2 \mathrm{M} \mathrm{NaOH}$ was added. The mixture was shaken and the $\mathrm{pH}$ of the aqueous layer was confirmed to be within the range $2.5-2.8 .^{11}$ The aqueous solution (1) was reserved for further treatment. The BuOH layer was extracted with $10 \mathrm{ml}$ of $2 \mathrm{mM} \mathrm{HCl} 4$ times; thus, aqueous solutions (2) - (5) were obtained.

To the aqueous solution (5), $8 \mathrm{ml}$ of $\mathrm{BuOH}$ was added. After shaking, the BuOH layer was removed. The aqueous layer was combined with the aqueous solution (4). To the solution $8 \mathrm{ml}$ of $\mathrm{BuOH}$ was added and shaken, and the BuOH layer was removed. The aqueous layer was combined with the aqueous solution (3) and treated in the same way mentioned above. These operations were repeated until the aqueous solution (1) was treated. To the accumulated aqueous solution, $4 \mathrm{ml}$ of $\mathrm{BuOH}$ was added. After shaking once more, the BuOH layer was removed. The aqueous solution of MTB, thus obtained, was $58 \mathrm{ml}$.

The $\mathrm{pH}$ of the aqueous solution was adjusted to 1.5 by adding $37 \% \mathrm{HCl}$; the solution was then evaporated under vacuum. The residue was dissolved into $45 \mathrm{ml}$ of BuOH. Ten milliliters of $0.03 \mathrm{M} \mathrm{HCl}$ were added to the $\mathrm{BuOH}$ solution. After shaking the solution, the aqueous layer was removed. The BuOH layer was extracted with $3 \mathrm{ml}$ of $0.03 \mathrm{M} \mathrm{HCl} 5$ times.

The BuOH solution was evaporated under vacuum. A dark-red residue was treated with $25 \mathrm{ml}$ of water at $40^{\circ} \mathrm{C}$. One part of the residue soon changed into a reddish-orange powdery precipitate. After all of the residue disappeared, the mixture was cooled with an ice bath. The precipitate was filtered and washed with cold water. It was first dried in air and then under vacuum in a silica-gel desiccator at room temperature for $5 \mathrm{~d}$.

\section{Results and Discussion}

\section{Liquid-liquid distribution equilibria}

In order to choose the best conditions for solvent extraction, the distribution ratio of MTB, Semi-Methylthymol Blue (SMTB), Thymol Blue (TB), and IDA between $\mathrm{BuOH}$ and aqueous phases, $D=C_{\mathrm{BuOH}} / C_{\mathrm{aq}}$, were determined at various $\mathrm{pH}$ under a constant chloride concentration of $0.25 \mathrm{M}$ with $\mathrm{HCl}$ and sodium chloride $(\mathrm{NaCl})$. The value of $D_{\text {Tв }}$ at $\mathrm{pH} 3.8$ was $10^{2.6}$ and that of $D_{\text {SMTB }}$ at $\mathrm{pH} 4.3$ was $10^{0.1}$. The other results are shown in Fig. 1 in a plot of $\log D$ versus the $\mathrm{pH}$ of the aqueous phase.

MTB had a maximum $D$ of 4 around pH 1.5, where

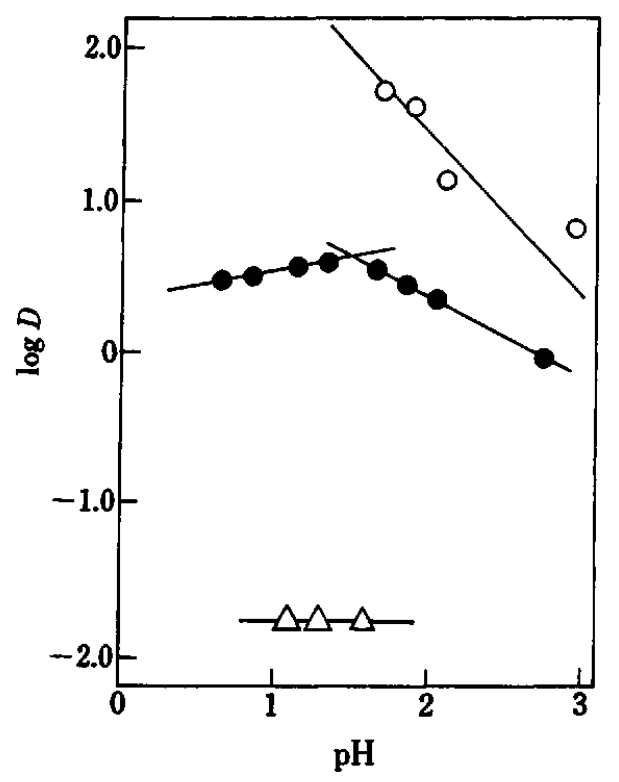

Fig. $1 \log D$ vs. pH of MTB (๑), SMTB (O) and IDA $(\Delta)$ between 1-butanol and $0.25 \mathrm{~mol} \mathrm{dm}^{-3}$ aqueous sodium chloride as a function of $\mathrm{pH}$ of aqueous phase at $20 \pm 2^{\circ} \mathrm{C}$. 
a neutral species, $\mathrm{H}_{6} \mathrm{MTB}$, is considered to be the predominant one. ${ }^{12}$ The $\log D$ decreased linearly with either an increase or decrease in $\mathrm{pH}$ in both sides of the maximum; the slopes of the lines were -0.5 at $\mathrm{pH} 1.6-3$ and 0.16 at $\mathrm{pH} 0.6-1.2$. The fact that the absolute values of the slopes of the two lines were smaller than 1 suggests that the ion pairs such as $\mathrm{H}_{7} \mathrm{MTB}^{+}-\mathrm{Cl}^{-}$and $\mathrm{H}_{5} \mathrm{MTB}^{-}-\mathrm{Na}^{+}$and/or $\mathrm{H}^{+}$distribute into the $\mathrm{BuOH}$ phase $^{13}$ together with $\mathrm{H}_{6} \mathrm{MTB}$. Ion pairs of $\mathrm{HTB}^{-}-\mathrm{Na}^{+}$ and $\mathrm{HTB}^{-}-\mathrm{H}^{+}$have been found to play a major role in extracting TB to BuOH. ${ }^{14}$ At pH $2.7 D_{\text {MTB decreased }}$ to less than 1, or MTB became more distributed in an aqueous phase than in the BuOH phase.

The distribution ratio of SMTB, $D_{\mathrm{SMTB}}$, was much larger than $D_{\text {MTB }}$ (see Fig. 1) but smaller than $D_{\text {Tв. The }}$ $D_{\text {SMTB }}$ increased with a decrease in $\mathrm{pH}$; it exceeded 50 at pH 1.6. A profile of $\log D$ versus $\mathrm{pH}$ may be interpreted by a straight line with the slope of -1 at pH 1.5 to 2 (see Fig. 1); the neutral species, H$_{4}$ SMTB, is considered to contribute mainly to the extraction of SMTB ${ }^{13,15}$ in the $\mathrm{pH}$ region.

The distribution ratio of IDA was 0.02 between pH 1.1 and 1.6, i.e., most of IDA remains in the aqueous phase as a univalent cation. ${ }^{16}$

The $D$ values decreased in the order TB $>$ SMTB $>$ MTB $\gg$ IDA. The order is the same as that of the hydrophobicity of the series of compounds; the hydrophobicity of the TB moiety must be weakened by a substitution of the hydrophilic IDA moiety.

\section{Synthesis and pretreatment of crude Methylthymol Blue}

The synthetic reaction mixture was examined by SPSephadex chromatography. Three bands were observed: the 1 st band (41\%, TB and SMTB), the 2 nd band (58\%, MTB) and the $3 \mathrm{rd} \cdot$ band (1\%, unidentified). ${ }^{17}$

A pretreatment of the reaction mixture of MTB was carried out in order to remove sodium acetate prior to solvent extraction; otherwise, acetic acid, formed by sodium acetate and $\mathrm{HCl}$, increases the content of water in the BuOH phase and, thus, increases the solubility of both MTB and IDA to the BuOH phase.

\section{Purification of Methylthymol Bhe by solvent extraction}

On the basis of the distribution ratio, $\mathrm{pH}$ values of 1.4-1.5 and 2.5-2.8 were chosen for the extraction of IDA and MTB, respectively, from the BuOH phase to the aqueous phase. Extraction at a $\mathrm{pH}$ region higher than 2.8 was avoided since SMTB and/or MTB made the system emulsive.

In the Recommended Procedure described above, crude MTB was first distributed between $\mathrm{BuOH}$ and aqueous hydrochloric acid $(\mathrm{HCl})$ at $\mathrm{pH} 1.5$ in order to remove most of the IDA into the aqueous phase. MTB in the BuOH phase was then extracted into an aqueous phase at pH 2.8-2.5, leaving SMTB and TB in the BuOH phase. A small amount of the remaining IDA was removed by extracting again at $\mathrm{pH} 1.4-1.5$ with aqueous $\mathrm{HCl}$. The extraction procedure was repeated until IDA could not be detected in the aqueous layer (checked by a DEAE-Sephadex chromatography and ninhydrin colorimetry).

The MTB residue evaporated from the BuOH solution was treated with water in order to remove chloride and sodium. A dark-red MTB residue gradually dissolved in water and turned to a reddish-orange powdery precipitate, suggesting an electronic configurational change in the TB moiety. A stable form of free acid, $\mathrm{H}_{6} \mathrm{MTB} \cdot 3 \mathrm{H}_{2} \mathrm{O}$, was obtained.

MTB reacts with BuOH to form esters and with water to be hydrolysed, especially at higher $\mathrm{pH}$. In order to avoid such reactions purification must be practiced rapidly at a temperature lower than $25^{\circ} \mathrm{C}$, unless otherwise noticed. The whole purification procedure required only $1.5 \mathrm{~d}$, except for drying the obtained powder, even on a scale 10-times larger than that for the recommended procedure. The purification yield was $70 \%$ and the purity was as high as that of the recommended procedure.

In order to purify a commercial MTB sodium salt', $1 \mathrm{~g}$ of the dye was dissolved into $17 \mathrm{ml}$ of water, followed by the addition of $0.7 \mathrm{ml}$ of $37 \% \mathrm{HCl}$ to adjust pH 1.4-1.5. Seventy milliliters of BuOH were added to the solution and the mixture shaken. Further treatment was the same as the Recommended Procedure.

\section{Confirmation of the purity of Methylthymol Blue obtained}

Elemental analyses of the MTB powder, thus obtained, agreed with the formula $\mathrm{H}_{6} \mathrm{MTB} \cdot 3 \mathrm{H}_{2} \mathrm{O}$; Found: C, 54.72; $\mathrm{H}, 6.43 ; \mathrm{N}, 3.42 ; \mathrm{S}, 3.95 \%$. Calcd for $\mathrm{C}_{37} \mathrm{H}_{50} \mathrm{~N}_{2-}$ $\mathrm{O}_{16} \mathrm{~S}: \mathrm{C}, 54.80 ; \mathrm{H}, 6.21 ; \mathrm{N}, 3.46 ; \mathrm{S}, 3.95 \%$. Complete removal of IDA was confirmed again on the basis of these results. It contained a very small amount of chlorine (less than the analytical limit) and sodium $(0.02 \%)$. The SP-Sephadex chromatography of the product showed only a single band, confirming that SMTB and other byproduct dyes were completely removed.

The apparent molar absorption coefficient $\varepsilon^{\text {app }}$ of the MTB was 18350 at $440 \mathrm{~nm}$, close to a value found in the literature, $18900 .^{7}$ The $\varepsilon^{\text {app }}$ of iron(III)-MTB complex, $\mathrm{Fe}_{2} \mathrm{MTB}$, was obtained directly from the absorbance under the condition that the iron(III) concentration $(0.01 \mathrm{M})$ had a large excess over MTB $(19.3 \mu \mathrm{M})$ in $0.05 \mathrm{M} \mathrm{HCl}$. The value of 43400 at $622 \mathrm{~nm}$ was considerably larger than that reported $(36700 \text { at } 625 \mathrm{~nm})^{18}$, reflecting especially the complete removal of SMTB.

A mole ratio study was performed in order to determine the composition of the complex of cobalt(II) with MTB $(19.3 \mu \mathrm{M})$ under the conditions of $\mathrm{pH} 9.0$ (borate buffer), an ionic strength of $I=0.1 \mathrm{M}\left(\mathrm{KNO}_{3}\right)$ and a temperature of $25^{\circ} \mathrm{C}$. A break in the absorbance (measured at $618 \mathrm{~nm}$ ) appeared at a mole ratio of 2.0:1

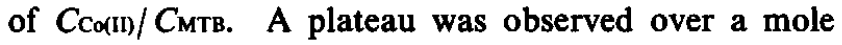
ratio of $2.2: 1$ to $4.4: 1$. From the absorbance in the plateau region, the molar absorption coefficient of $\mathrm{Co}_{2} \mathrm{MTB}^{2-}$ was calculated to be $44500 .^{19}$ This value is 
significantly larger than that reported(35700). ${ }^{20}$ All of the results confirmed the high purity of the MTB obtained by the present method.

The absorbance of the cobalt(II) complex at $619 \mathrm{~nm}$ changed with temperature as $0.856\left(26^{\circ} \mathrm{C}\right), 0.824\left(36^{\circ} \mathrm{C}\right)$, and $0.820\left(40^{\circ} \mathrm{C}\right)$, suggesting that the complex is thermochromic.

The authors express their hearty thanks to Professor Yuko Hasegawa of Science University of Tokyo and to Professor Akihiko Yamagishi of the University of Tokyo for their helpful advice during this work.

\section{References and Notes}

1. C. J. Kantipuly and A. D. Westland, Talanta, 35, 1 (1988).

2. K. L. Cheng, K. Ueno and T. Imamura, "Handbook of Organic Analytical Reagents," CRC Press, Boca Raton, Florida (1982).

3. T. N. Van der Walt and P. J. Fourie, Appl. Radiat. Iscot., 38, 158 (1987); S. C. Lavale, J. Electrochem. Soc. India, 35, 231 (1986).

4. V. N. Azarova and A. I. Kirillov, Zh. Anal. Khim., 41, 2004 (1986); Z. Ni and Y. Ma, Fenxi Huaxue, 13, 20, (1985); Y. K. Agrawal and P. T. Thomaskutty, Analyst [London], 112, 1015 (1987); S. B. Meshkova, Yu. V. Korovin and N. S. Poluektov, Zh. Fiz. Khim., 59, 1716 (1985).

5. MTB of Dojindo Lab. contained $61 \%$ of dye (on the formula of $\mathrm{Na}_{4} \mathrm{H}_{2} \mathrm{MTB}$ ) on the basis of $\varepsilon^{\mathrm{app}}$ at $440 \mathrm{~nm}$. The ratio of the absorbance of the iron(III) complex with respect to the free dye $(622 \mathrm{~nm} / 440 \mathrm{~nm})$ was 2.4 . Colorless impurities (39\%) are considered to be about $2 \mathrm{~mol}$ of $\mathrm{Na}$, IDA and $\mathrm{H}_{2} \mathrm{O}$ with respect to $1 \mathrm{~mol}$ of $\mathrm{Na}_{4} \mathrm{H}_{2} \mathrm{MTB}$ based on the AAS measurement and DEAESephadex chromatography. MTB of Kanto Chem. contained $65 \%$ of dye, and the absorption ratio $(622 \mathrm{~nm} /$ $440 \mathrm{~nm}$ ) was 2.0 .

6. S. Tachiyashiki, 38th Annual Meeting of the Chemical Society of Japan, 2H21, (1978), Nagoya.

7. T. Yoshino, H. Imada, T. Kuwano and K. Iwasa, Talanta, 16, 151 (1969).

8. S. Nakada. M. Yamada, T. Ito and M. Fujimoto, Bull. Chem. Soc. Jpn., 53, 3365 (1980); ibid., 53, 2252 (1980).

9. N. F. Kosenko, T. V. Mal'kova and K. B. Yatsimirskii, Zh. Anal. Khim., 32, 2450 (1977).

10. Deprotonation of carboxyl groups in MTB or SMTB caused a little shift of absorption maximum (at most $5 \mathrm{~nm}$ ) without any change in molar absortion coefficient. ${ }^{15,20}$
11. In case that the $\mathrm{pH}$ was out of range recommended, aqueous $\mathrm{NaOH}$ or $\mathrm{HCl}(\geq 1 \mathrm{M})$ was used to adjust $\mathrm{pH}$. The pH must be measured after shaking, since solutes (MTB and impurities) in the BuOH phase react with the acid-base buffers.

12. The result is consistent with the acid formation constants of $k_{6}=10^{1.820}$, and $k_{7}=10^{0.78}$ (B. Budesinsky, Z. Anal. Chem., 209, 247 (1965)), but not with $k_{6}=10^{1.13}$ (B. Budesinsky, ibid.).

13. T. Sekine and Y. Hasegawa, "Solvent Extraction Chemistry", M. Dekker, New York (1977); T. Sekine, "Shinjikken Kagaku Koza, Kihon Sosa I", pp. 253-291, ed. T. Tachibana, Maruzen, Tokyo (1978); Y. Yamamoto and E. Iwamoto, "Shinjikken Kagaku Koza, Bunseki Kagaku II", pp. 31-57, ed. T. Tachibana, Maruzen, Tokyo (1978).

14. The TB exists as HTB- in water at $\mathrm{pH} \mathrm{4}$, with an absorption maximum at $440 \mathrm{~nm}$. The BuOH solution of $\mathrm{TB}$, obtained by the distribution between $\mathrm{BuOH}$ and water $(\mathrm{pH}=4.1)$, showed two absorption maxima with comparable intensities at $415 \mathrm{~nm}$ and $540 \mathrm{~nm}$, assigned to HTB- $^{-}$and $\mathrm{H}_{2}$ TB, respectively. On the other hand the $\mathrm{BuOH}$ solution obtained by shaking with a $0.25 \mathrm{M}$ aqueous $\mathrm{NaCl}$ showed only one absorption maximum at $440 \mathrm{~nm}$ with a small shoulder at $540 \mathrm{~nm}$, indicating that the equilibrium $\mathrm{H}_{2} \mathrm{~TB} \rightleftharpoons \mathrm{HTB}^{-}+\mathrm{H}^{+}$shifted to the righthand side in the $\mathrm{BuOH}$ solution. The $\mathrm{pH}$ of the aqueous phase was 3.8, 0.3 unit smaller than that of the aqueous phase without $\mathrm{NaCl}$ or, in other words, $\mathrm{H}^{+}$with the same amount $(80 \mu \mathrm{M})$ as produced by the reaction $\mathrm{H}_{2} \mathrm{~TB} \rightarrow$ $\mathrm{HTB}^{-}+\mathrm{H}^{+}$in the BuOH phase transferred to the aqueous phase. Thus, $\mathrm{Na}^{+}$as that of $\mathrm{H}^{+}$, must exist as a counter ion of $\mathrm{HTB}^{-}$in the $\mathrm{BuOH}$ phase, or $\mathrm{HTB}^{-}$must be extracted to $\mathrm{BuOH}$ as an $\mathrm{HTB}^{-}-\mathrm{Na}^{+}$ion pair.

15. The result is consistent with the acid formation constant of $k_{A}=10^{2.0}$ (T. Yoshino, S. Murakami and M. Kagawa, Talanta, 21, 199(1974)).

16. The acid formation constant $k_{3}=10^{1.82}$ (N. A. Skorik and V. N. Kumok, J. Gen. Chem. (USSR), 37, 1461 (1967)).

17. The complex of this dye with iron(III) showed absorption maximum at $622 \mathrm{~nm}$, the same wavelength as that of MTB-Fe(III) complex. However, the ratio of the absorbance of the complex with repect to the free dye $(622 \mathrm{~nm} / 440 \mathrm{~nm})$ was 1.8 (2.4 for MTB).

18. N. F. Kosenko, Zh. Neorg. Khim., 28, 129 (1983).

19. The same value was obtained for ammonia-ammonium nitrate buffer, the same system as in a literature. ${ }^{20}$

20. T. Yoshino, H. Imada, S. Murakami and M. Kagawa, Talanta, 21, 211 (1974).

(Received August 23, 1988) (Accepted October 15, 1988) 